\title{
Superinfections in COVID-19 Patients: Role of Antimicrobials
}

\author{
Vijaya Lakshmi Nag Navneet Kaur \\ Department of Microbiology, All India Institute of Medical Sciences, Jodhpur, India
}

\section{Keywords}

COVID-19 · Superinfections · Antimicrobials .

Antimicrobial resistance

\begin{abstract}
The coronavirus pandemic is a global health crisis of recent times and the biggest threat we have faced after the Second World War. This viral infection (COVID-19) is not the only cause of deaths in this pandemic. A usual complication of viral infections is a secondary superimposed bacterial infection or a superinfection. Based on limited published data, the relatively high incidence of severe infection and mortality in COVID-19 patients is attributed to these infections. It is reasonable to anticipate that nearly half of the patients who have died from COVID-19 had superinfection. Patients who have severe form of the disease and those requiring prolonged stay in intensive care units (ICUs) are more prone to developing super added infec-
\end{abstract}

tion by nosocomial pathogens. The most common type of infection observed among COVID-19 patients is ventilator-associated pneumonia (VAP), followed by bacteremia with sepsis and urinary tract infections (UTIs). Antibiotics are commonly prescribed to keep these infections at bay which is promoting antimicrobial resistance (AMR). In developing countries like India, where there is well-established high burden of multidrug-resistant organisms in hospital settings, superinfections in COVID-19 patients can pose a biggest challenge in the treatment leading to increase mortality. There is a need of prospective studies, which should include clinical, microbiological, and epidemiological data on superinfections that can be used in forming effective antimicrobial stewardship strategies; which can have a crucial role in optimal antimicrobial prescribing.
(C) 2021 The Author(s).

Published by S. Karger AG, Basel karger@karger.com www.karger.com/dmj

Karger $\stackrel{\text { ' }}{5}$

GOPEN ACCESS
(C) 2021 The Author(s).

Published by S. Karger AG, Basel

This is an Open Access article licensed under the Creative Commons Attribution-NonCommercial-4.0 International License (CC BY-NC) (http://www.karger.com/Services/OpenAccessLicense), applicable to the online version of the article only. Usage and distribution for commercial purposes requires written permission.
Correspondence to:

Vijaya Lakshmi Nag, vijayalakshmi005@gmail.com 


\section{Introduction}

COVID - 19 has swiftly emerged as a pandemic causing significant morbidity and mortality accounting for over 8,00,000 deaths worldwide [1]. Regardless of its viral origin, a usual practice by clinicians is to initiate antibiotic therapy because fever and radiological proof of infiltrates are regarded as hallmarks of bacterial community-acquired pneumonia, which requires treatment by antibiotics [2]. Additionally, the reason for prolonged use of broad-spectrum antimicrobials in severely ill hospitalized patients is to either prevent or to manage infections acquired nosocomially based on earlier experience with influenza [3]. This has led to widespread inappropriate use of antibiotics.

The definite incidence of bacterial superinfections in COVID-19 is not known so far; it seems to be lower than in severe influenza cases $[4,5]$. A few reports, mostly from China, have reported secondary infections in the range of $5-27 \%$ of severe acute respiratory syndrome (SARS)-CoV-2 infected adults in several hospitals, which included $50-100 \%$ of those who died [6-12]. These infections are more commonly seen in patients with severe disease who are critically ill and in intensive care receiving mechanical ventilation. The reported incidence of super added infection in intensive care unit (ICU) cases ranges between 13.5 and $44 \%$ in patients with COVID-19, the most frequent type of infection seen is ventilator-associated pneumonia (VAP) due to bacterial or fungal causes, followed by bacteremia with sepsis and urinary tract infections (UTIs) $[8,12,13]$. An association between COVID-19 and superinfection can be possibly attributed to major lung damage caused by viral replication which results in cytokine storm and complex inflammatory processes.

In developing countries like India, where there is well-established high burden of multidrug-resistant organisms in ICU settings, superinfections in COVID-19 patients can pose a biggest challenge in the treatment leading to increase mortality. Effective antibiotic stewardship has a crucial role in limiting unnecessary use of antimicrobials and is "need of the hour." Superinfections are well documented in influenza and other respiratory viral illnesses $[14,15]$. However, data related to COVID-19 are limited and still emerging. No prospective studies have specifically investigated COVID-19 superinfections till date.

In this article, we review the constrained published data on bacterial and fungal superinfections among
COVID-19 patients, and provide view on role of antimicrobials, antimicrobial resistance (AMR), and antimicrobial stewardship. Studies included in the review were identified by PubMed search conducted from May 01, 2020, to July 30, 2020, using terms "COVID-19," "novel coronavirus," "superinfections," "Role of antimicrobials in COVID-19," "Antimicrobial resistance" and "Antimicrobial Stewardship." We also included studies from 2003-2018 done on SARS and influenza.

\section{Superinfections and Risk Factors}

Bacterial and fungal superinfections occur more commonly in critically ill hospitalized patients with risk factors such as advanced age, underlying systemic diseases, patients with immunosuppression, corticosteroid use, mechanical ventilation, and prolonged hospital and ICU stays [7] though relatively uncommon, superinfections can also complicate coronavirus disease in an immunocompetent patient $[8,9]$.

\section{Possible Pathophysiology of Superinfections}

Following viral infection, mechanical, and immunological mechanisms impair the host defenses of the respiratory tract, which may leave the patient vulnerable to bacterial and fungal proliferation [10]. Two non-exclusive mechanisms, which predispose a patient to superinfection are as follows:

1 Mechanical ventilation.

2 Dysregulation of the immune system of the host.

The interplay between virus and host cell induces immune response which results in synthesis of pro-inflammatory cytokines such as interleukin-6, interleukin-2, soluble interleukin-2 receptor, tumor necrosis factor-alpha, and anti-inflammatory cytokines, for example, interleukin-4 and interleukin-10, which proves harmful to host cells. This cytokine release syndrome, exhaustion of immune system, and lung damage may predispose to acquiring superinfection. In severe cases, induced cytokine storm, decreased CD4 and CD8 T cells, and suppressed interferon-gamma production by CD4 T cells have been correlated with disease severity $[11,12]$. The cytokine analysis is costly and not routinely employed by majority of the laboratories, surrogate inflammatory markers such as $\mathrm{C}$-reactive protein (CRP), and procalcitonin (PCT) can be done to recog- 
nize critically ill patients. The serial PCT measurement plays an important role for predicting evolution towards more severe COVID-19 disease. Its production and subsequent release into circulation from extra thyroidal sources is tremendously boosted in bacterial infections and actively sustained by interleukin- 6 and tumor necrosis factor-alpha. However, the biomarker's synthesis is inhibited by interferon-gamma, which is present in high concentrations during viral infections, so PCT value stays within the reference range in uncomplicated COVID-19 patients, and its significant rise would reflect super added bacterial infection or severe form of disease [11].

\section{Definitions}

Superinfection is diagnosed when the patients exhibited clinical signs and symptoms of pneumonia or bacteremia combined with a positive culture of a new pathogen from a lower respiratory tract samples (including the sputum, transtracheal aspirates, or bronchoalveolar lavage fluid) or blood samples taken $\geq 48 \mathrm{~h}$ after admission [13]. VAP is identified based on 3 criteria: new or progressive persistent radiographic infiltrates, clinical observations suggesting infection (new onset of fever, purulent sputum, leukocytosis, increased minute ventilation, arterial oxygenation decline and/or need of vasopressors, and high PCT/CRP), and positive microbiological culture [14, 15]. Sepsis and septic shock are defined according to the 2016 third international Consensus Definition for sepsis and septic shock [13]. Catheter-associated UTI is defined as a UTI where an indwelling urinary catheter is in place for more than 2 calendar days on the date of event, with day of device placement being day 1 , and an indwelling catheter in place on the date of event or the day before [16].

\section{Types of Superinfection}

The most usual type of infection noted in hospitalized COVID-19 patients is pneumonia (VAP) followed by bacteremia and UTIs [17].

\section{Ventilator-Associated Pneumonia}

Mechanical ventilation is frequently required by severe COVID-19 patients admitted in ICUs along with heavy sedation, prone positioning, and muscle block- ers for prolonged period which can increase the risk of acquiring secondary nosocomial infection mainly ventilator-associated pneumonia (VAP). Mechanical ventilation has been reported among 21-88\% ICU patients in COVID-19 case series in various studies [4, 18-23]. The clinical picture of COVID-19 pneumonia is indistinguishable from VAP; therefore, the microbiological evidence from deep respiratory secretions presently remains the sole criterion to support diagnosis in such patients [15]. A retrospective study done on 918 patients in China, reported VAP in $32.3 \%$ cases, while Zhou and colleagues [24] documented VAP in 10 of 32 patients needing invasive mechanical ventilation [17]. Another study reported hospital-acquired pneumonia associated with mechanical ventilation in $20 \%$ cases among survivors and 6\% cases in non-survivors [18].

\section{Bacteremia}

Blood stream infections seem uncommon in COVID-19 patients. A study from New York City hospitals reported very low rate of true bacteremia (1.6\%) among COVID-19-positive patients [25]. Low rates of bacteremia have also been reported among patients with SARS [26, 27]. In a study done by Yang et al. [18], bacteremia was seen in 3\% cases among non-survivors of COVID-19 patients. In contrast, He et al. [17] documented bacteremia in $24.6 \%$ cases.

\section{Urinary Tract Infection}

The prevalence of hospital-acquired urinary tract infections (UTIs) ranges between $1.4-3.3 \%$ and urinary catheters representing the major risk factor associated with acquiring UTI in hospitalized patients [28]. However, the data among COVID-19 patients are inadequately reported and investigated. A study done by Yang et al. [18] reported UTI in 3\% cases.

\section{Etiological Agents of Superinfections}

Superinfections related to COVID-19 have been observed to be caused by bacterial and fungal agents as per various studies $[9,29]$.

\section{Bacterial Agents}

Bacterial superinfections can significantly increase the morbidity and mortality of viral infections especially in critically ill patients [30]. Two studies from China reported secondary bacterial infection in 47.6 and $42.8 \%$ cases, respectively [ 31,32$]$. The elevated risk for bacterial superinfection may be attributed to lymphopenia in more than $80 \%$ reported COVID-19 pa- 
tients. Direct infection of $\mathrm{T}$ cells and depletion has been studied in SARS and the impaired lymphocyte defense resulting in bacterial secondary infections [33].

The various organisms cultured from COVID-19 patients includes multidrug-resistant Klebsiella pneumoniae, Pseudomonas aeruginosa, Serratia marcescens, Enterobacter cloacae, Acinetobacter baumannii, Escherichia coli, Staphylococcus aureus, and Bacillus cereus $[25,31,34,35]$,

\section{Fungal Agents}

Severe COVID-19 patients requiring intensive care may also be at risk of acquiring fungal superinfection. Alveolar damage facilitating invasion by fungus and acute respiratory distress syndrome are frequently associated with invasive pulmonary aspergillosis in the ICU; a well-supported hypothesis [36]. Invasive aspergillosis is a well-documented complication of severe influenza pneumonia [37]. In an autopsy-based study, during 2003 SARS outbreak, 10\% (2/20) had invasive aspergillosis [38]. A few of the most common fungal agents documented to cause superinfection in COVID-19 patients are Aspergillus flavus, Aspergillus fumigatus, Candida albicans, and Candida glabrata $[9,34]$. Tables 1 and 2 summarizes clinical studies citing superinfections in COVID-19 patients.

\section{Empirical Use of Antimicrobials}

The data review from COVID-19 cases largely from China found that more than $70 \%$ of the patients received antimicrobial therapy, while less than $10 \%$ on an average had bacterial or fungal superinfection or coinfections [5]. Antimicrobial agents have been typically used empirically rather than against diagnosed infection because it is difficult to rule out bacterial and fungal superinfections based on signs and symptoms alone.

In a study done on 52 critically ill adult patients, antibacterial agents were started empirically in $95 \%$ of cases [18], while Zhou and colleagues [24] noted secondary infections in 50\% non-surviving patients and antibiotic use rate was $94-100 \%$ [29]. One more study from China reported antibiotic use in $97 \%$ of confirmed COVID-19 patients. In a study conducted on 1,099 patients, intravenous antibiotics and antifungal were administered in 58 and $2.8 \%$ cases, respectively, and the majority of the patients who had received these therapies had severe disease, including mechanical ventilation $[39,46]$.
A retrospective study carried by Buetti et al. [47] assessed the impact of early administration of antibiotics (i.e., before ICU admission) on mortality and delay in hospital-acquired infections. In their study, a total 48 COVID-19 patients were enrolled and the patients were divided into 2 groups on the basis of whether the patient received antibiotic or not. A total of 19 patients were given antibiotics before ICU admission because of suspicion of superinfection. They reported that both groups (with and without antibiotics) had similar outcomes in terms of mortality with no statistically significant findings with respect to delayed hospital-acquired infections during ICU stay. However, it was observed that UTIs were frequent in the without antibiotic group, and candidemia was experienced more in the antibiotic group [40].

The most common antibiotics used empirically at several hospitals in Wuhan, included azithromycin, fluoroquinolones, cephalosporins, carbapenems, vancomycin, and linezolid. However, the details on susceptibility patterns and dosing are unavailable $[6,7,20$, $21,41]$. Voriconazole (minimum inhibitory concentration $0.125 \mathrm{mg} / \mathrm{L}$ ) was used for the treatment of invasive aspergillosis caused by Aspergillus fumigatus [48, 49].

Gibinigie and colleagues [50] after reviewing the effectiveness and safety of azithromycin in treating COVID-19 concluded that there was paucity of evidence to support the use of azithromycin for the COVID-19 treatment outside the context of clinical trials, unless it is used to treat bacterial superinfection, and there are very limited data on a possible synergy between azithromycin and hydroxychloroquine.

In March 2020, Duployez et al. [40] recorded a case of pneumonia caused by Staphylococcus aureus secreting Panton Valentine Leukocidin toxin, which complicated COVID-19 in a 30-year-old man admitted in ICU with mechanical ventilation. Initially he was treated with oxacillin plus clindamycin and azithromycin for COVID-19, which was later changed to piperacillin-tazobactam and linezolid and then to meropenem, gentamicin, and linezolid; however, the patient died after 17 days of admission. In 2003, during the SARS$\mathrm{CoV}$ outbreak, there was an increase in $S$. aureus superinfection causing VAP, the similarities between SARS-CoV-2 and previous coronaviruses, and methicillin-resistant Staphylococcus aureus warrants the need for empirical coverage with antibiotics in ICU settings based on the local antibiogram in countries with high organism burden [40]. 
As per the National Institute for Health and Care Excellence, UK (May 2020), the treatment guidance for severe hospital-acquired pneumonia in COVID-19 patients includes broad-spectrum antibiotics such as piperacillin-tazobactam, ceftazidime and levofloxacin. Vancomycin, teicoplanin and linezolid if MRSA is suspected [45].

\section{Outcome}

Two studies from China among laboratory confirmed cases, reported the median duration of illness onset to ICU admission and subsequent development of secondary infection has 10.5 and 17 days (13-19 days), respectively. The median time to death was $18-5$ days indicating that superinfections were often end events $[13,24]$ In a study done on 179 hospitalized patients in China, the clinical condition of $21(11.7 \%)$ patients worsened in a short time-span and the mean duration from admission to death was 13.7 days. The reason was attributed to presence of secondary bacterial infection [47].

Yang and colleagues [18] in their study on 52 critically ill patients with COVID-19 documented mechanical ventilation in 37 patients, the median duration from onset of symptoms to ICU admission was 9.5 days. Mortality was seen in 32/37 cases, the median duration from admission to ICU and death was 7 days. Twenty-one (40\%) patients had chronic diseases, including cerebrovascular diseases in $7(13-5 \%)$ patients. Among non-survivors, secondary infections were observed in 4 patients with highly drug-resistant organisms.

He et al. [17] reported that the mortality of COVID-19 patients with nosocomial infections was $15.4 \%$, which was remarkably higher than COVID-19 patients with no nosocomial infections. Invasive devices, diabetes, glucocorticoid treatment, and combination of antibiotics were found to be significant predictors of nosocomial infections.

\section{BIOMARKERS (PCT and CRP)}

In a meta-analysis, the risk of severe COVID-19 infection was seen to be 5 times more in patients with raised PCT. The patients who had raised PCT at the time of admission had significantly higher risk of developing secondary bacterial infection [52].

In a study involving 1,099 patients, 2 groups were made based on disease severity: severe (173) and nonsevere (926). Mechanical ventilation was required in 61 patients among the severe group. Majority of the pa-

Superinfections in COVID-19 Patients tients had raised CRP (81.5\%) and PCT (13.7\%) levels in the severe group as compared to CRP (56.4\%) and PCT (3.7\%) among the non-severe group [49].

In addition, CRP lacks specificity for bacterial infections and it rises late in infection, while PCT increases promptly within 6-12 h upon stimulation and can differentiate between bacterial and viral systemic infections and true bacteremia from contaminated blood cultures. It has better discriminatory ability than CRP and white blood count [53]. Randomized controlled trials conducted as per the type of infection documents that PCT, when used for diagnosis, can reduce the antibiotic exposure in hospitals in VAP and severe sepsis/ shock $[54,55]$. Although measurements of PCT may be an important tool to limit antimicrobial use, the suboptimal specificity of PCT should be considered always as elevated levels, and it may also occur in advanced stages of COVID-19 without proven bacterial co- or superinfection [2].

In contrary to the above data on superinfections, studies conducted in 2 hospitals on 788 hospitalized patients and 24 patients in ICU observed no incidence of superinfections $[4,56]$. Some case series on COVID-19 has not provided information on superinfections in their studies [21,23]; it is doubtful if superinfection events were not found in these patients, or simply the data were not furnished.

The reason for discordant observations between different studies may be attributed to different hospital antibiotic policies and also institutional ecology. The low incidence of superinfections observed with respect to COVID-19 could be due to the high mortality in severely ill patients and under reporting of data.

\section{Implications and Ideas for Future Research}

This study explored research studies, and the data are lacking on superinfections and antimicrobial use in COVID-19 patients; however, all the findings reviewed are in favor of superinfections, which are more common in hospitalized severely ill patients, with frequency in ICU patients. Since COVID-19 is still affecting a large cohort of people and these infections have adverse outcomes in certain groups, current studies are insufficient regarding how much is the actual impact of these infections on disease severity and outcomes in such patients. Further prospective large multicenter studies on superinfection in COVID-19 patients are imminently required.

High rate of antimicrobial prescribing has been recognized, which ultimately leads to AMR. The use of 
azithromycin is endorsed by the WHO to only cover bacterial superinfections, and the shortage of azithromycin has already been reported to the FDA. One of the reasons why antibiotic use is going on almost across the board is the lack of rapid diagnosis of bacterial superinfections due to non-availability of specific costeffective and rapid diagnostic tests.

The empirical use of antimicrobials should be reserved for severely ill COVID-19 patients, with constant reassessment of their necessity and should be stopped as early as possible if the bacterial superinfection probability is considered low (e.g., negative bacteriologic tests, persistently low inflammatory biomarkers, and CT scan non-compatible with COVID).

There are very limited data on bacterial and fungal secondary infections and among hundreds of studies, only a very few reports secondary infections and that also without detailed causative pathogens and their antibiotic susceptibility profile. Almost all the studies are from China, which may limit the generalizability of the findings. No study specifies the data regarding Clostridium difficle infection, which is associated with the use of broad-spectrum antibiotics.

As India has some of the highest rates of antibiotic use and multidrug-resistant pathogens, there is a need for strict infection control practices in the intensive care setting, potential antimicrobial stewardship interventions and carefully designed large individual prospective studies investigating exact incidence of $\mathrm{CO}$ VID-19 superinfections, and AMR pattern.

Antimicrobial stewardship principles can help guiding in appropriate use of antibiotics and should include reserving antibiotics for severe cases, collection of necessary microbiology samples before antibiotics, daily assessment of possible de-escalation based on microbiology results and clinical judgment, and short duration as possible. Further research is also needed in current infection control guidelines, which are only aimed to prevent transmission and cross-infection by COVID-19, and misses the prevention of bacterial or fungal hospital-acquired infections. Strict and effective infection control policies should be made to prevent patients from acquiring nosocomial infections, and there is a need for time-to-time revision of these policies. As pandemic is a signal to global policy makers, there is a continuous need for research for the development of newer classes of antibiotics.

\section{Conclusion}

Superinfections are a major risk factor for adverse outcome in COVID-19, and hospitalized patients with severe disease are more susceptible to developing these infections. An estimated 1 in 7 COVID-19 patients develop superinfection while hospitalized. Rapid diagnosis of secondary bacterial infections can improve the outcome, especially in high-risk groups, so there is a continuous need of prospective studies for assessing the diagnostic performance of biomarkers to rule out or rule in bacterial superinfection. Antibiotics are commonly prescribed to keep these infections at bay especially in ICUs, which is promoting AMR. Epidemiological, clinical, and microbiological data on hospitalacquired superinfections are needed to update antimicrobial stewardship that is crucial in optimal antimicrobial prescribing. Adherence to rigorous infection prevention practices in hospitals is crucial in limiting nosocomial infections. Further, the emergence of COVID-19 is a sharp reminder for continuous and urgent need for the research and development of newer antimicrobials in future. 


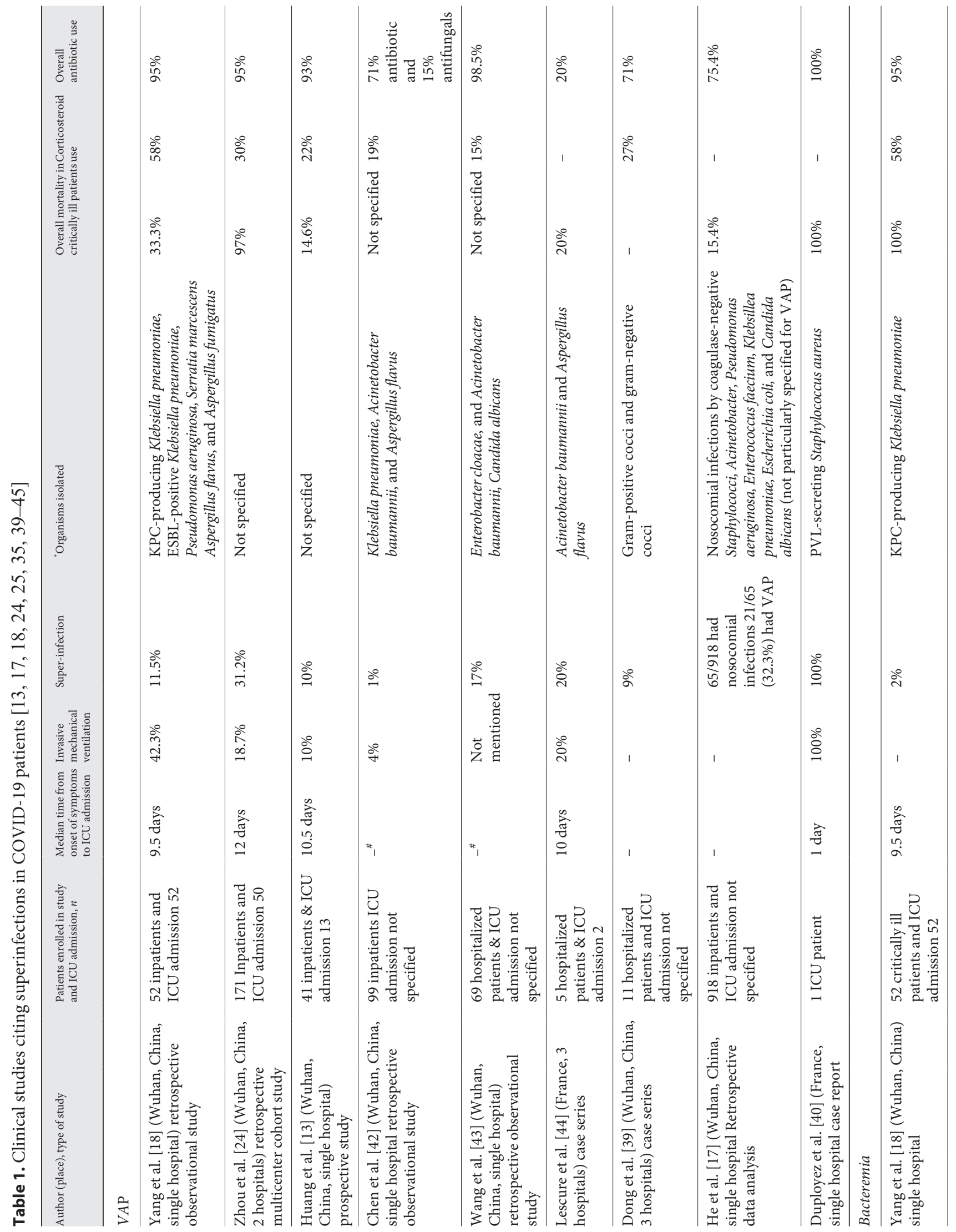




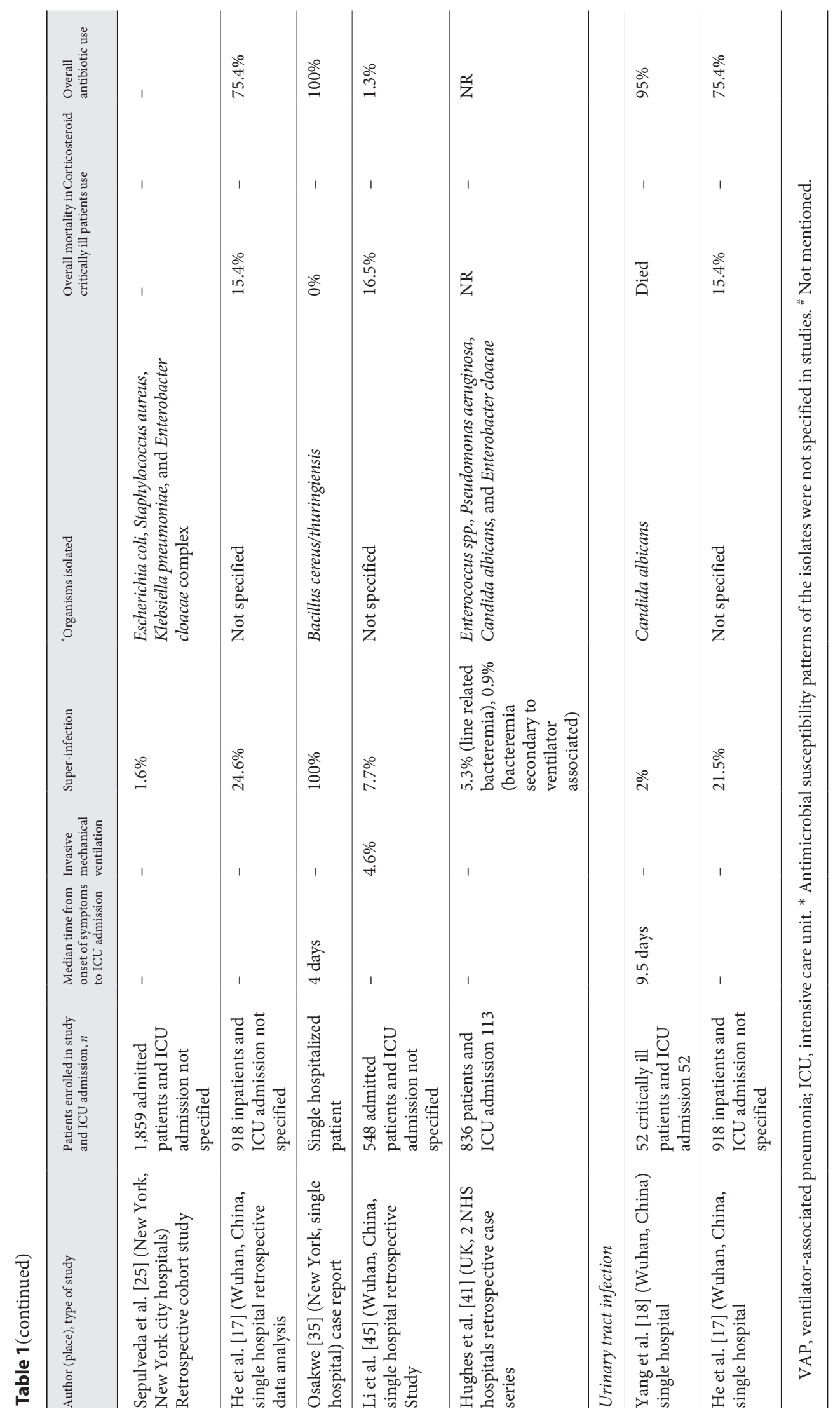


Table 2. Summary of etiological agents implicated in superinfections among COVID-19 patients

\begin{tabular}{|c|c|c|c|}
\hline Etiological agent & VAP/secondary pneumonia & Bacteremia & UTI \\
\hline Bacterial agents & $\begin{array}{l}\text { Klebsiella pneumoniae, Pseudomonas } \\
\text { aeruginosa, Serratia marcescens, } \\
\text { Acinetobacter baumannii, Enterobacter } \\
\text { cloacae, and Staphylococcus aureus }\end{array}$ & $\begin{array}{l}\text { Klebsiella pneumoniae, } \\
\text { Coagulase negative, Staphylococci, } \\
\text { Staphylococcus aureus, } \\
\text { Escherichia coli, } \\
\text { Enterobacter cloacae complex, } \\
\text { Bacillus cereus/thuringiensis, } \\
\text { Enterococcus species, and } \\
\text { Pseudomonas aeruginosa }\end{array}$ & Not specified \\
\hline Fungal agents & $\begin{array}{l}\text { Aspergillus flavus, Aspergillus fumigates, } \\
\text { and Candida albicans }\end{array}$ & Candida albicans & $\begin{array}{l}\text { Candida albicans and } \\
\text { Candida glabrata }\end{array}$ \\
\hline
\end{tabular}

VAP, ventilator-associated pneumonia; UTI, urinary tract infection.

\section{Conflict of Interest Statement}

The authors have no conflicts of interest to declare.

\section{Funding Sources}

The authors have no financial relationships relevant to this article to disclose.

\section{Author Contributions}

V.L.N. conceptualized the study and suggested the title; V.L.N. and N.K. searched and critically analyzed the literature published on the topic and wrote the manuscript. All authors read and approved the final manuscript.

\section{References}

1 World Health Organization. Coronavirus Disease (COVID-19) pandemic. Available from: https://www.who.int/emergencies/diseases/novel-coronavirus-2019.

2 Huttner BD, Catho G, Pano-Pardo JR, Pulcini C, Schouten J. COVID-19: don't neglect antimicrobial stewardship principles!. Clin Microbiol Infect. 2020;26:808-10.

3 Klein EY, Monteforte B, Gupta A, Jiang W, May L, Hsieh YH, et al. The frequency of influenza and bacterial coinfection: a systematic review and meta-analysis. Influenza Other Respir Viruses. 2016;10(5):394-403.

4 Bhatraju PK, Ghassemieh BJ, Nichols M, Kim $\mathrm{R}$, Jerome KR, Nalla AK, et al. Covid-19 in critically Ill patients in the seattle region: case series. N Engl J Med. 2020;382:2012-22.

5 Rawson TM, Moore LSP, Zhu N, Ranganathan N, Skolimowska K, Gilchrist M, et al. Bacterial and fungal co-infection in individuals with coronavirus: a rapid review to support COVID-19 antimicrobial prescribing. Clin Infect Dis. 2020;71:2459-68.ciaa530.

6 Cao J, Tu WJ, Cheng W, Yu L, Liu Y-K, Hu X, et al. Clinical features and short-term outcomes of 102 patients with corona virus disease 2019 in Wuhan, China. Clin Infect Dis. 2020.ciaa243.
7 Chen T, Wu D, Chen H, Yan W, Yang D, Chen G, et al. Clinical characteristics of 113 deceased patients with coronavirus disease 2019: retrospective study. BMJ. 2020 Mar 26; 368:m1091.

8 Jose M, Desai K. Fatal superimposed bacterial sepsis in a healthy coronavirus (COVID-19) patient. Cureus. 2020;12(5):e8350.

9 Blaize M, Mayaux J, Nabet C, Lampros A, Marcelin A, Thellier M, et al. Fatal Invasive aspergillosis and coronavirus disease in an immunocompetent patient. Emerg Infect Dis. 2020;26(7):1636-7.

10 Alp E, Voss A. Ventilator associated pneumonia and infection control. Ann Clin Microbiol Antimicrob. 2006;5(1):7.1

11 Hendaus MA, Jomha FA. Covid-19 induced superimposed bacterial infection. J Biomol Struct Dyn. 2020:1-7.

12 Pedersen SF, Ho YC. SARS-CoV-2: a storm is raging. J Clin Invest. 2020;130(5):2202-5.

13 Huang C, Wang Y, Li X, Ren L, Zhao J, Hu Y, et al. Clinical features of patients infected with 2019 novel coronavirus in Wuhan, China. Lancet. 2020;395(10223):497-506.

14 Chastre J, Luyt CE. Does this patient have VAP? Intensive Care Med. 2016;42(7):115963.
15 François B, Laterre PF, Luyt CE, Chastre J. The challenge of ventilator-associated pneumonia diagnosis in COVID-19 patients. Crit Care. 2020;24(1):289.

16 Centres for Disease Control and Prevention. Urinary tract infection (catheter associated urinary tract infection and non catheter associated urinary tract infection) events; 2020. 7-1-19.

17 He Y, Li W, Wang Z, Chen H, Tian L, Liu D. Nosocomial infection among patients with COVID-19: a retrospective data analysis of 918 cases from a single center in Wuhan, China. Infect Control Hosp Epidemiol. 2020;13: $1-2$.

18 Yang X, Yu Y, Xu J, Shu H, Liu H, Wu Y, et al. Clinical course and outcomes of critically ill patients with SARS-CoV-2 pneumonia in Wuhan, China: a single-centered, retrospective, observational study. Lancet Respir Med. 2020

19 Goyal P, Choi JJ, Pinheiro LC, Schenck EJ, Chen R, Jabri A, et al. Clinical characteristics of Covid-19 in New York city. N Engl J Med. 2020;382:2372-4. 
20 Du Y, Tu L, Zhu P, Mu M, Wang R, Yang P, et al. Clinical features of 85 fatal cases of COVID-19 from Wuhan. A retrospective observational study. Am J Respir Crit Care Med. 2020;201:1372-9.

21 Wang D, Hu B, Hu C, Zhu F, Liu X, Zhang J, et al. Clinical characteristics of 138 hospitalized patients with 2019 novel coronavirus-infected pneumonia in Wuhan, China. JAMA. 2020;323(11):1061-9.

22 Arentz M, Yim E, Klaff L, Lokhandwala S, Riedo FX, Chong M, et al. Characteristics and outcomes of 21 critically ill patients with COVID-19 in Washington State. JAMA. 2020; 323(16):1612-4.

23 Grasselli G, Zangrillo A, Zanella A, Antonelli M, Cabrini L, Castelli A, et al. Baseline characteristics and outcomes of 1591 patients infected with SARS-CoV-2 admitted to ICUs of the Lombardy Region, Italy. JAMA. 2020; 323(16):1574-81.

24 Zhou F, Yu T, Du R, Fan G, Liu Y, Liu Z, et al. Clinical course and risk factors for mortality of adult inpatients with COVID-19 in Wuhan, China: a retrospective cohort study. Lancet. 2020;395(10229):1054-62.

25 Sepulveda J, Westblade LF, Whittier S, Satlin MJ, Greendyke WG, Aaron JG, et al. Bacteremia and blood culture utilization during $\mathrm{CO}$ VID-19 surge in New York City. J Clin Microbiol. 2020;58:00875-20.

26 Leong HN, Earnest A, Lim HH, Chin CF, Tan C, Puhaindran ME, et al. SARS in Singapore: predictors of disease severity. Ann Acad Med Singap. 2006;35(5):326.

27 Peiris JS, Chu CM, Cheng VC, Chan KS, Hung IF, Poon LL, et al. Clinical progression and viral load in a community outbreak of coronavirus-associated SARS pneumonia: a prospective study. Lancet. 2003;361(9371): 1767-72.

28 Nicastri E, Leone S. Guide to infection control in the healthcare setting hospital-acquired urinary tract infection. Int Soc Infect Dis. 2018 Feb.

29 Zhou P, Liu Z, Chen Y, Xiao Y, Huang X, Fan $\mathrm{XG}$. Bacterial and fungal infections in COVID-19 patients: a matter of concern. Infect Control Hosp Epidemiol. 2020;1:1-2.

30 Gupta RK, George R, Nguyen-Van-Tam JS. Bacterial pneumonia and pandemic influenza planning. Emerging Infect Dis. 2008;14(8): 1187.

31 Du R-H, Liang L-R, Yang C-Q, Wang W, Cao T-Z, Li M, et al. Predictors of mortality for patients with COVID-19 pneumonia caused by SARS-CoV-2: a prospective cohort study. Eur Respir J. 2020;55(5):2000524.
32 Wang L, He W, Yu X, Hu D, Bao M, Liu H, et al. Coronavirus disease 2019 in elderly patients: characteristics and prognostic factors based on 4-week follow-up. J Infect. 2020; 80(6):639-45.

33 Chen WC, Lai YC, Lin CH, Zheng JF, Hung WC, Wang YJ, et al. First COVID-19 mortality case in Taiwan with bacterial co-infection by national surveillance of critically ill patients with influenza-negative pneumonia. J Microbiol Immunol Infect. 2020.

34 Lansbury L, Lim B, Baskaran V, Lim WS. Coinfections in people with COVID-19: a systematic review and meta-analysis. J Infect. 2020;81:266-75.

35 Osakwe N. A case of Bacillus cereus bacteremia in a COVID-19 patient treated with steroids. IDCases. 2020;21:e00855.

36 Blot S, Rello J, Koulenti D. Diagnosing invasive pulmonary aspergillosis in ICU patients: putting the puzzle together. Curr Opin Crit Care. 2019;25(5):430-7.

37 Schauwvlieghe AFAD, Rijnders BJA, Philips N, Verwijs R, Vanderbeke L, Van Tienen C, et al. Invasive aspergillosis in patients admitted to the intensive care unit with severe influenza: a retrospective cohort study. Lancet Respir Med. 2018;6(10):782-92.

38 Hwang DM, Chamberlain DW, Poutanen SM, Low DE, Asa SL, Butany J. Pulmonary pathology of severe acute respiratory syndrome in Toronto. Mod Pathol. 2005;18(1): $1-10$

39 Dong X, Cao YY, Lu XX, Zhang JJ, Du H, Yan $\mathrm{Y} \otimes \mathrm{Q}$, et al. Eleven faces of coronaviris disease 2019. Allergy. 2020;75.

40 Duployez C, Le Guern R, Tinez C, Lejeune $\mathrm{AL}$, Robriquet L, Six S, et al. Panton-valentine leukocidin-secreting staphylococcus aureus pneumonia complicating COVID-19. Emerg Infect Dis. 2020;26(8):1939.

41 Hughes S, Troise O, Donaldson H. Bacterial and fungal coinfection among hospitalized patients with COVID-19: a retrospective cohort study in a UK secondary care setting. Clin Microbiol Infect. 2020;26:1395-9.

42 Chen N, Zhou M, Dong X, Qu J, Gong F, Han $\mathrm{Y}$, et al. Epidemiological and clinical characteristics of 99 cases of 2019 novel coronavirus pneumonia in Wuhan, China: a descriptive study. The Lancet. 2020;395(10223):507-13. [Accessed Feb 15].

43 Wang Z, Ye D, Wang M, Zhao M, Li D, Ye J, Liu J, Xu Y, Zhang J, Pan W, Liu M. Clinical Features of COVID-19 Patients with Different Outcomes in Wuhan: A Retrospective Observational Study. BioMed Research International. 2020 Oct 5;2020.
44 Lescure FX, Bouadma L, Nguyen D, Parisey $\mathrm{M}$, Wicky PH, Behillil S, et al. Clinical and virological data of the first cases of COVID-19 in Europe: a case series. The Lancet Infectious Diseases. 2020 Jun;120(6):697-706.

45 Li Q, Guan X, Wu P, Wang X, Zhou L, Tong Y, Ren R, Leung KS, Lau EH, Wong JY, Xing $\mathrm{X}$. Early transmission dynamics in Wuhan, China, of novel coronavirus-infected pneumonia. New England Journal of Medicine. 2020

46 Guan WJ, Ni ZY, Hu Y, Liang WH, Ou CQ, $\mathrm{He}$ JX, et al. Clinical characteristics of coronavirus disease 2019 in China. N Engl J Med. 2020;382(18):1708-20.

47 Buetti N, Mazzuchelli T, Lo Priore E, Balmelli C, Llamas M, Pallanza M, et al. Early administered antibiotics do not impact mortality in critically ill patients with COVID-19. J Infect. 2020;S0163-4453(20):30381-9.

48 Wang Z, Yang B, Li Q, Wen L, Zhang R. Clinical features of 69 cases with coronavirus disease 2019 in Wuhan, China. Clin Infect Dis. 2020;71(15):769.

49 Prattes J, Valentin T, Hoenigl M, Talakic E Reisinger AC, Eller P. Invasive pulmonary aspergillosis complicating COVID-19 in the ICU-A case report. Med Mycol Case Rep. 2020.

50 Gbinigie K, Frie K. Should azithromycin be used to treat COVID-19? A rapid review. BJGP Open. 2020;4:1-8.

51 National Institute for Health and Care Excellence. COVID-19 rapid guideline: antibiotics for pneumonia in adults in hospital (NICE guideline 173); 2020. Available from: https:// www.nice.org.uk/guidance/ng173/chapter/2.

52 Lippi G, Plebani M. Procalcitonin in patients with severe coronavirus disease 2019 (COVID-19): a meta-analysis. Clin Chim Acta. 2020;505:190-1.

53 Schuetz P, Albrich W, Mueller B. Procalcitonin for diagnosis of infection and guide to antibiotic decisions: past, present and future. BMC Med. 2011;9:107-9.

54 Bouadma L, Luyt CE, Tubach F, Cracco C, Alvarez $A$, Schwebel $C$, et al. PRORATA trial group: use of procalcitonin to reduce patients' exposure to antibiotics in intensive care units (PRORATA trial): a multicentre randomised controlled trial. Lancet. 2010;375:463-74.

55 Stolz D, Smyrnios N, Eggimann P, Pargger H, Thakkar N, Siegemund M, et al. Procalcitonin for reduced antibiotic exposure in ventilatorassociated pneumonia: a randomised study. Eur Respir J. 2009;34(6):1364-75.

56 Lian J, Jin X, Hao S, Cai H, Zhang S, Zheng L, et al. Analysis of Epidemiological and Clinical features in older patients with corona virus disease 2019 (COVID-19) out of Wuhan. Clin Infect Dis. 2020;25:ciaa242. 